Revista Iberoamericana, Vol. LXXVII, Núm. 235, Abril-Junio 2011, 501-515

\title{
UNA MEMORIA QUE OBLIGA: EL NEXUS DE NANCY MOREJÓN
}

\author{
POR \\ IneKe Phaf-RheInBerger \\ Humboldt University of Berlin \\ University of Maryland
}

Este ensayo se concentra en el papel de la memoria sobre la trata de esclavos en la obra de Nancy Morejón. En su introducción a la antología bilingüe de su poesía, Juanamaría Cordones-Cook escribe que esta memoria está siempre presente en ella. Cordones-Cook (2003) desprende esta afirmación del poema "Mujer Negra" (1975), un texto en el que se reconstruye la historia de la esclavitud africana y la diáspora. El poema se abre con los versos siguientes:

\section{Todavía huelo la espuma del mar que me hicieron atravesar. La noche, no puedo recordarla. \\ Ni el mismo océano podría recordarla. (Cuerda 113)}

En general, las imágenes del mar, de las aguas, de las cartas náuticas, de los ríos y de los barcos abundan en la obra de Morejón. Sin embargo, en este ensayo se arguye que en Carbones silvestres (2005), uno de sus poemarios más recientes, se agrega a este imaginario acuático una dimensión histórica que se nutre de una tradición decimonónica. Corresponde con el motivo que Paul Gilroy, en su libro The Black Atlantic. Modernity and Double Consciousness (1993), concibe como la imagen de un barco atravesando el mar, entendida como un microcosmos político y cultural, cuyo movimiento se define como el símbolo organizador de la vida moderna:

I have settled on the image of ships in motion across the spaces between Europe, America, Africa, and the Caribbean as a central organizing symbol for this enterprise and as my starting point. The image of the ship-a living, micro-cultural, micro-political system in motion - is especially important for historical and theoretical reasons that I hope will become clearer below. (4)

En la opinión de Cheryl Finley (2004), este ícono movedizo representa una "memoria" que "obliga", y se refiere para esto a los comienzos de la protesta política sistemática 
contra la trata, vinculándola con los esfuerzos abolicionistas en Inglaterra. Finley describe el famoso panfleto de Thomas Clarkson, cuyos 1500 ejemplares se imprimieron el 29 de diciembre de 1788 con la meta de sensibilizar al parlamento inglés y a otras organizaciones sobre las circunstancias inhumanas de la trata de esclavos. El panfleto muestra un diagrama del corte longitudinal de un barco negrero, visto desde arriba, en el que se visualiza la disposición de las personas en la planta más baja. El diagrama no deja ninguna duda acerca de las condiciones de estrechez, sobrecargo, y la falta de aire y espacio del cargamento de hombres, embalados y dispuestos como cualquier mercancía. A partir de entonces surgiría una crítica tradición poética y pictográfica del barco negrero, de la que el poema "Das Sklavenschiff" (1853-1854) de Heinrich Heine y el cuadro "Slavers Throwing Overboard the Dead and Dying" (1840) del pintor J. M. W. Turner son sólo algunos de los ejemplos más conocidos.

Para la historia cultural del siglo XIX no se trata exclusivamente del barco negrero sino, en general, del topos del barco en el mar -con o sin cargamento de esclavos- que se apropiaría del imaginario como la metáfora paradigmática para expresar el deseo de libertad, de fuga de las restricciones de las naciones europeas y de emprender viajes llenos de aventuras y peligros hacia países lejanos. Elizabeth DeLoughrey entiende este desarrollo en su estudio Routes and Roots (2007) como la consecuencia de una nueva filosofía espacial, de un "imaginario oceánico" (DeLoughrey 23-25, 27) que concibe el "barco como una nación" (15). Esta filosofía coincide con una era de acelerada expansión colonizadora y, de acuerdo con esta dinámica, se relegaban islas y ciudades portuarias lejanas a una periferia poseedora de una "cultura arcaica" (17), la contraparte de una sociedad moderna. Estas tierras fueron consideradas como una mera extensión del barco, sin una dinámica histórica propia. Según DeLoughrey, esta representación colonial influye aún en la iconografía de los anuncios contemporáneos destinados a atraer el turismo. Más importante aún, discute en Routes and Roots una tradición literaria que corresponde con o deconstruye estos estereotipos, dando así a conocer la dinámica de una historia propia de los lugares antes considerados como inhabitados y aislados.

DeLoughrey se limita al análisis de la literatura escrita en inglés y discute extensivamente el efecto de la "Robinsonade", el éxito explosivo y permanente de Robinson Crusoe, el libro de Daniel Defoe, a partir de la fecha de su primera publicación en 1719. Sin embargo, el ícono del barco que navega sobre los mares y su naufragio se encuentra asimismo en la literatura escrita en español, portugués, francés, alemán y holandés a partir del siglo XVI. ${ }^{1}$ No obstante, el acento en el barco como ícono movedizo es algo del siglo XIX y uno de los poemas modelos en este sentido es "Le Bateaux ivre" (1871) de Arthur Rimbaud, que concibe el cuerpo flotante del yo lírico en el mar

1 Todavía no existe un detallado estudio comparativo sobre este tema. Beatriz Pastor ya se referió en Discurso narrativo de la conquista de América (1983) al mito del naufragio en la literatura española de la conquista.

$\begin{array}{lllll}\text { Revista Iberoamericana, Vol. LXXVII, Núm. 235, Abril-Junio 2011, } & 501-515 \\ \text { ISSN 0034-9631 (Impreso) }\end{array}$ 
tempestuoso de manera análoga a un barco (Sämtliche Dichtungen 132-39). Rimbaud escribe este poema en la métrica de 25 cuartetos en rima alejandrina y lo caracteriza él mismo como "le poème de la mer". De esta manera provoca el efecto de movimiento, tempestad, oleada, y cielo nublado con viento y menciona dos veces que observa descender a los ahogados ("le noyé pensif", "des noyés descendaient dormir") en las aguas del mar. Asimismo hace una doble mención del hecho de que este barco, entre otros productos, es portador de algodón inglés ("de cotons anglais", "porteurs de cotons"), una figura que establece una asociación explícita con el origen de su producción, el trabajo de campo en las plantaciones de América del Norte.

\section{MOREJón Y RiMBAUd}

La obra de Morejón, lectora devota de la poesía de Rimbaud, contiene numerosas referencias a la obra de este poeta francés. Abundan ejemplos. El barco ebrio de Rimbaud se manifiesta en su poema "Nexus" (Cuerda 40-42) que tiene como tema el alma peregrina de los barcos, sea de una piragua indígena o de un "gran barco ebrio llamado Nexus". La autora publicó sus traducciones de los poemas "Royauté" (de Les Illuminations) y "Délires II" (de Une Saison en Enfer) en una edición especial en Matanzas, en ocasión del centenario de la muerte de Rimbaud, en 1991. Una de las tres dedicatorias del volumen Paisaje célebre (1993) reproduce la frase: "J'ai seul la clef de cette parade sauvage", un verso tomado de Les Illuminations (1872-1873). Y en Carbones silvestres (2005), el último poema "La mano es oscurísima" (84) lleva la dedicatoria: "bonne pensée du matin", citado del mismo volumen del autor francés.

Se encuentran muchas más referencias a Rimbaud en la poesía de Morejón, quien empezó a leerlo a principios de la década de 1960, en la época de las grandes transformaciones políticas en su país. Esto explica que le inspirasen las protestas y exclamaciones enfáticas del "poeta maldito" francés quien, como ocurre en "Démocratie", no se cansará de cuestionar la fe ilimitada en el progreso: "Nous massacrerons les révoltes logiques" (Rimbaud, Sämtliche Dichtungen 244), además de enunciar en "Mauvais sang" su protesta identificándose con una bestia, un negro: "Oui, $\mathrm{j}$ 'ai les yeux fermés à votre lumière. Je suis une bête, un nègre. Mais je puis être sauvé" (Rimbaud, Sämtliche Dichtungen 274).

Giovanni Berjola, en su estudio Arthur Rimbaud et le complexe du damné (2007), sostiene que el poeta reactualizará su infierno imaginario en su posterior experiencia como negociante en Oriente y en Etiopía. La percepción de Morejón es diferente. En su ensayo "Hablar de Rimbaud" recuerda que, en aquellos años de estudio de la literatura francesa en la Escuela de Artes y Letras de La Habana, la lectura de Rimbaud le inspiró para elaborar un proyecto nuevo. Buscaba conversaciones sobre el tema. Menciona la importancia de su primera conversación con Fayad Jamís que se centró en las obras

Revista Iberoamericana, Vol. LXXVII, Núm. 235, Abril-Junio 2011, 501-515 
fundamentales de Rimbaud: Las iluminaciones y Una temporada en el infierno. En su opinión, La Habana se convertía en esos años "en una encrucijada insustituible, en una cierta capital para el desarrollo de ideas, valores y su consecuente difusión. Una vida literaria sin precedentes, se abría paso en medio de convulsiones históricas" (Ensayos 288). Sobre este fondo la autora percibe la obra del poeta francés como una fuente de felicidad. En su texto sobre Rimbaud, originalmente una conferencia del 26 de octubre de 2004 brindada en ocasión de la conmemoración del 150 aniversario de su natalicio, Morejón comenta:

Haber leído y traducido a Rimbaud fue una de las experiencias más deslumbrantes de mi carrera literaria en Cuba. En su compañía, descubrí óperas fabulosas, la humedad de los trastos viejos e incorporé esa necesidad suya de la belleza, todos los días. (Ensayos 297)

La importancia de la belleza, todos los días, igualmente es el tema de sus palabras pronunciadas al recibir el Premio Nacional de Literatura 2001, "La belleza en todas partes", donde la poeta menciona otra vez el papel extraordinario de aquellos primeros años de la Revolución Cubana:

Aunque el tránsito de un dominio a otro fue algo lento, puedo afirmar que culminó entre el verano y el otoño de 1962 cuando apenas había cumplido diecisiete años de edad. Había entrado a una Universidad regida por la Reforma Universitaria - gestada por varias generaciones-y por el más sano espíritu de solidaridad intelectual. (Cuerda 5)

Esta coincidencia entre el espíritu rebelde de Rimbaud y la realidad de La Habana revolucionaria se ha inscrito como fijeza en la obra de Morejón. Al resumir las enseñanzas recibidas de este poeta francés, la poeta menciona tres elementos como fundacionales para su propia obra: 1) el don del que ve relacionado con un sentimiento de integración del entorno, del medio ambiente, de la naturaleza como hecho de alta prioridad; 2) un desdoblamiento, al afirmar que ese Yo no es tal sino Otro, "Je suis un autre", dando nacimiento así a lo que la poesía en tiempos modernos reconoce como el yo poético cuya cualidad primordial reside en la exclusión del yo biográfico, sustituido, por cualquier otra experiencia vital o libresca; 3) el conocimiento de la alucinación como categoría absoluta, generadora de los contrastes que alimentan a su vez a la metáfora y, luego, eficaz herramienta traída al terreno del proceso creador (Ensayos 291-92).

Se nota que, con este resumen, Morejón se refiere al efecto de la lectura de Rimbaud en un momento clave de articular una concepción poética propia. Con respecto a este hecho, se encuentra en buena compañía. Con frecuencia se ha llamado la atención sobre la influencia de Rimbaud en la obra de los surrealistas y de poetas como Aimé Césaire (Arnold 42-43; Veit-Wild 44-45). También resuena en autores africanos, quienes al

Revista Iberoamericana, Vol. LXXVII, Núm. 235, Abril-Junio 2011, $501-515$
ISSN 2154-4794 (Electrónico) 
"escribir locura" y delinear las "líneas fronterizas del cuerpo" (Veit-Wild 39) adoptan la rebeldía de Rimbaud y su dinamitar las normas decimonónicas, evocando otros horizontes de la realidad con la ayuda de técnicas tales como el quiasmo, el paralelismo, la repetición, la alusión, el oxymoron, la hipérbole, la asonancia o la aliteración. Este arsenal les ayuda en su esfuerzo de desestabilizar el modelo colonizador del pasado, mediante la productividad "loca" de un poeta visionario.

\section{El ARRAIGO EN LA LITERATURA CUBANA}

Pese a su gran afición por la lengua francesa, manifestada en sus traducciones de Rimbaud, Édouard Glissant y Patrick Chamoiseau, Morejón se entiende como parte íntegra de la tradición literaria de Cuba, con el español como su medio de expresión privilegiado. Ha declarado con frecuencia que Nicolás Guillén -el Poeta Nacional de Cuba- es una presencia fundacional en su obra. En su discurso de ingreso a la Academia Cubana de la Lengua, España en Nicolás Guillén (2005), explica que su arraigo profundo en la lengua española se debe al hecho de que Guillén había "amulatado" su métrica. Menciona además que, de acuerdo con Cintio Vitier, su hallazgo de la estructura formal del son constituye uno de los aportes más valiosos a la poesía cubana. Morejón elogia el mérito de otros logros formales en la obra de Guillén:

[...] un verso amplio, discursivo, en el que el yo poético se ajusta al yo vital y viceversa; un verso de molde clásico de arte mayor o menor según convenga al propósito del autor en el que, a ratos, el yo poético no es un yo sino un nosotros -épico más bien; un monólogo plural, proveniente del nosotros whitmaniano-, al que integra formas propias de la híbrida cultura nacional. Un verso breve, de nominaciones elípticas, útil al poeta para la sátira y ejercitado tanto en sus sones como en sus epigramas y madrigales. (España 13)

Elverso breve, de nominaciones elípticas, influye en el poema "Mississipi"(Carbones 59), dedicado a Nicolás Guillén. En tres tercetos de versos breves se retrata la presencia de una "serpiente del agua" "junto" o "entre" los sauces del Golfo, mientras que los otros tres cuartetos de versos amplios evocan el panorama extendido de "Carabelas, fantasmas, pieles quemadas".

Sin disminuir el papel primordial de Guillén, valga la pena recordar que, en la obra de Morejón, Guillén no constituye la única influencia cubana. La autora comparte su admiración por Rimbaud con otro autor, José Lezama Lima. En el artículo “A propósito de José Lezama Lima", publicado en la Gaceta de Cuba en 1970, defiende su papel para

2 Es interesante observar que, en general, la crítica especializada en la literatura africana suele considerar a Aimé Césaire, de Martinica, como a un autor africano.

Revista Iberoamericana, Vol. LXXVII, Núm. 235, Abril-Junio 2011, 501-515 
la literatura cubana en un momento en el que se consideraba a Lezama como un poeta demasiado hermético. Morejón contradice esta opinión. Observa que Lezama es un poeta con una clara referencialidad antillana: "El poeta aborda el trauma, los contextos geográficos y filosóficos de la insularidad, ya vulnerada por el genio visionario de Nicolás Guillén" (Ensayos 198).

Lezama escribió repetidas veces sobre Rimbaud hasta elaborar una interpretación propia de su "poème de la mer", incluido en los Fragmentos a su imán (1978), un volumen de publicación póstuma. Contiene el poema "Una fragata, con las velas desplegadas, gira golpeada por la tempestad, hasta insertarse en un círculo transparente, azul inalterable, en el lento cuadriculado de un prismático" (64-65). Está firmado con fecha de abril de 1971, es decir el mes del airado debate internacional sobre el devenir de la política cultural de Cuba. ${ }^{3}$ En la obra de Lezama La Habana figura como un punto de referencia permanente. En el ensayo "La calle de Rimbaud", incluido en Tratados en La Habana (1958), arguye que la poesía del autor francés necesita las calles de su nativa ciudad portuaria:

\begin{abstract}
La tierra que erotiza su poesía necesita de esa calle que se extiende desde las empalizadas hasta el pintarrajeo portuario. Y en esa calle, ofrecida como una secreta granada salvaje, la catedral, el colegio, la librería, la casa del profesor rebelde, el placer, ferias, la jaula de mimbres, los sombreros turcos, las escarapelas. Y las bibliotecas convertidas en guarida, donde se refugia como escolar fugado, y convierte las lecturas en paisajes, en islas movedizas ancladas en una flora de agua. (105)
\end{abstract}

Al fijar la ciudad como "punto de avanzada" en la poesía de Rimbaud, Lezama explica que su lectura da una energía que se manifiesta como una descarga de pólvora extendida por toda la ciudad" (103). Morejón, a su vez, adopta el imaginario barroco de Lezama. Al igual que en su "Muerte de Narciso" (1937), con la doble figura de Narciso e Î́caro (Phaf y Walthaus 1980), Morejón conceptúa en "Paisaje célebre" (Cuerda 46) a Brueghel el Viejo como el pintor de "la soledad del alma". Se desarrolla la visión del cuadro Caída de Ícaro, en el que el yo lírico de Morejón ve caer a Ícaro en la bahía desde Alamar, el barrio habanero construido al nordeste de la bahía. Se imagina en sus alrededores un valle de "espléndidos labradores" y "árboles frutales" donde se encuentra un misántropo encapuchado arando sobre las aguas. El cuadro de Brueghel lo acompaña en su viaje a la ficción, expresado en la última frase enfática: "Es el atardecer y necesito las alas de Ícaro" (Cuerda 46).

3 La fecha de abril de 1971 se refiere automáticamente al caso Padilla en la UNEAC y al Primer Congreso Nacional de Arte y Literatura.

$\begin{array}{lllll}\text { Revista Iberoamericana, Vol. LXXVII, Núm. 235, Abril-Junio 2011, } & 501-515 \\ \text { ISSN 0034-9631 (Impreso) }\end{array}$ 
LOS “CARBONES” Y SU ARRAIGO EN EL SIGLO XIX

Queda claro que la filosofía del mar así como de la ciudad de La Habana desempeña un papel en la literatura cubana que influye en la obra de Morejón referiéndose a tiempos tan lejanos como el Barroco. Rimbaud, sin embargo, la une con Fayad Jamís como veíamos arriba. Por lo tanto, no sorprende que en el poema "Leer en la biblioteca de Fordham" (Cuerda 66), dedicado a la memoria de Jamís, Rimbaud se vislumbra en estos versos. Otra vez, nos situamos en la tarde del yo lírico en la que, al principio de los doce versos, se introduce la visión de una "aguja" y un "ahogado" empapados "de sales abatidas y mares rizadas/ que baten sus velámenes de un solo color y un solo grito”. Esta imagen de un barco en mares agitadas resulta de una lectura realizada "encima de esta mesa cuadrada/ rodeada de estantes metálicos, cuadriculados". La doble repetición del cuadrado/ cuadriculado indica que la lectura se realiza como en un cuadrado mágico, como el acto de evocar una memoria sagrada.

La palabra "carbones" del título Carbones silvestres sugiere que la visión del ahogado en el mar no sólo recuerda el poema de Rimbaud sino que también construye una puente con la literatura cubana del siglo XIX. Los "carbones" son el sujeto de una conversación en Cecilia Valdés (1886), la novela nacional de Cuba del autor Cirilo Villaverde. La trama se sitúa en la atmósfera de represión de La Habana experimentada por la llamada "generación de 1830" (Villaverde 132). El mismo Villaverde, miembro de esta generación, pudo haberse inspirado en muchas experiencias autobiográficas ocurridas durante sus estudios en La Habana entre los años 1823 y 1832. Además, en su novela sobre aquellos días, varias veces menciona como una fuente relevante de información a El Diario de La Habana, leído en las casas educadas de entonces. ${ }^{4}$

La conversación sobre los "carbones" se lleva a cabo entre Don Cándido y su esposa Rosa, refiriéndose al hecho de que el capitán del bergantín Veloz había echado al mar una parte de su carga clandestina, al darse cuenta de la cercanía de las patrullas inglesas. El dueño del buque, Don Cándido, usa la expresión "los sacos de carbón" o "los bultos" (Villaverde 240, 254, 275, 500) para indicar que la carga consistía de personas embaladas, objetos de mercancía de la trata clandestina, ya perseguida por las autoridades de Inglaterra. El negociante comenta que "los fardos de África no tienen alma", una opinión que Villaverde modifica al final de este capítulo:

Y, sin embargo, no le había dicho los medios de que pensaba valerse para arrancar el Veloz y la mayor parte de la carga, compuesta de seres humanos, diga él lo que quiera, de las garras de los testarudos ingleses. (Villaverde 247)

4 Existe un índice de este períodico de los años 1812 a 1848 compilado por el Dr. José A. Martínez Fortún y Foyo: El Diario de La Habana en la mano. Índices y sumarios.

Revista Iberoamericana, Vol. LXXVII, Núm. 235, Abril-Junio 2011, 501-515 ISSN 0034-9631 (Impreso) ISSN 2154-4794 (Electrónico) 
Villaverde describe todo lo ocurrido alrededor del Veloz muy detalladamente. El Veloz es un "famoso bergantín", "tan ufano y orgulloso cual si libre cortara las aguas del océano y no se hallara cautivo de los perros ingleses" (253). Además, pormenoriza los esfuerzos de Don Cándido y su mayordomo, Don Melitón Reventos, para recuperar gran parte de la mercancía confiscada por los ingleses, así como su diplomacia en relación al entorno del capitán general Francisco Dionisio Vives en el patio de la fortaleza La Fuerza. Villaverde comenta que en esta época de represión militar y corrupción la conspiración fue "un estado normal y permanente de una buena parte de la juventud cubana" (266). Para este autor, la represión de esta mentalidad conspiradora se vuelve fundamental para entender los eventos de 1844, cuando se "descubrió" la Conspiración de La Escalera, causando el fusilamiento de gran parte de la población libre y urbana. ${ }^{5} \mathrm{Al}$ atenerse a la descripción atmosférica y debido a la fidelidad a los hechos históricos, la novela de Villaverde consigue una dimensión que va mucho más allá de los "sugar secrets" (Kutzinski 1993), de los secretos de la vida erótica de la sociedad esclavista, el motivo preferido en los estudios críticos, las películas, las obras de teatro o las telenovelas. En efecto, relaciona la jerarquía social en la isla de Cuba con la "gramática marítima", con el Veloz y su microcosmos, según Gilroy el símbolo organizador de la sociedad moderna.

La modernidad está inscrita en Cecilia Valdés: alrededor de 1830 había en Cuba ferrocarriles, máquinas de vapor, y barcos modernos como el bergantín Veloz de Don Cándido, comprado en los Estados Unidos. De todas formas, la modernidad se relaciona de manera exclusiva con la economía de plantación, la economía explosiva de aquella época, inimaginable sin la labor esclava. Otro autor cubano, Lino Novás Calvo, menciona asimismo un barco llamado Veloz en la biografía novelada de Pedro Blanco, el negrero (1933). Cuenta la vida de Pedro Blanco, un personaje histórico nacido en España, cuyo negocio consistía en suministrar esclavos a los propietarios habaneros desde la costa de Gallinas (hoy en Sierra Leona), entre 1821 y 1836. En el libro de Novás Calvo, el Veloz leva anclas en Ajuda (Bahía de Benín), para cargar esclavos vendidos por el legendario

\footnotetext{
5 Al describir el baile de la gente de color en la calle de Jesús María, Villaverde caracteriza a algunos personajes de la manera siguiente: "[...] a Vargas y a Dodge, ambos de Matanzas, barbero el uno, carpintero el otro, que fueron comprendidos en la supuesta conspiración de la gente de color en 1844 y fusilados en el paseo de Versalles de la misma ciudad; a José de la Concepción Valdés, alias Plácido, el poeta de más estro que ha visto Cuba, y que tuvo la misma desastrada suerte de los dos precedentes; a Tomás Vuelta y Flores, insigne violinista y compositor de notables contradanzas, el cual en dicho año pereció en la Escalera, tormento a que le sometieron sus jueces para arrancarle la confesión de complicidad en un delito cuya existencia jamás se ha probado lo suficiente; al propio Francisco de Paula Uribe, sastre habilísimo, que por no correr la suerte del anterior, se quitó la vida con una navaja de barbear en los momentos que le encerraban en uno de los calabozos de la ciudadela de la Cabaña; a Juan Francisco Manzano, tierno poeta que acababa de recibir la libertad, gracias a la filantropía de algunos literatos habaneros" (Villaverde 365-366).
}

Revista Iberoamericana, Vol. LXXVII, Núm. 235, Abril-Junio 2011, $501-515$
ISSN 2154-4794 (Electrónico) 
Cha-Cha, apodo de Francisco Felix de Souza, comerciante y antiguo esclavo regresado de Brasil a África. ${ }^{6}$ Pedro se embarca en el Veloz, que tiene un cargamento de 800 esclavos $y$, pese a que la nave "navegaba como un cisne al nordoeste con galeno favorable" (108), el autor caracteriza la trayectoria como uno de los viajes más dramáticos de la trata.

La preocupación por el comercio de la trata es crucial en la lectura de Morejón. En su ensayo "Mito y realidad en Cecilia Valdés" (1979) lo entiende como la piedra angular de un sistema enfermo:

Para nadie es un secreto que la esclavitud africana en América, al igual que en otros continentes, fue una - por no decir la más- de las arcas que erigió y fortificó las bases del capitalismo europeo. El imperio colonial hispánico llegó a ser uno de los más vastos. La trata de negros africanos, que posibilitaría la implantación de un sistema enfermo desde sus fueros más profundos, fue el pivote, la piedra angular de la colonia, llamárase española, francesa, inglesa u holandesa. Por otra parte, la trata fue una de las constantes más firmes en las Antillas. Dicho status colonial, entre nosotros, creó una sociedad cuya estructura correspondería, perfectamente, al trazado de una pirámide egipcia. (Ensayos 5-6)

Como ya mencioné antes, la memoria del viaje del barco como motivo es el tema de "Leyendo en la biblioteca de Fordham", obviamente enfatizando su ilegalidad. El ahogado aparece acompañado de una "aguja", un pez típico de las zonas pantanosas del mar, en la cercanía de la costa. La presencia de esta aguja se explica al percatarse de que la lectura se realiza en la biblioteca de Fordham, de la universidad homónima en Nueva York. Esta universidad jesuita privada, en su página oficial de Internet, explica que el nombre "Fordham" deriva de las palabras "ford" y "ham", "meaning a wading place or ford by a settlement", por excelencia el lugar de desembarque de la mercancía clandestina. ${ }^{7}$ Morejón, sin dudas, está convencida de la importancia de esta memoria. Su yo lírico-lector es un "fiel velador" con "cejas selváticas", "acodado a esta mesa entre dos paisajes", situados en Guayos y en París - ambos lugares de residencia de Fayad Jamís, a quien se dedica este poema-.

6 Véase el artículo de Silke Strickrodt, "The Brazilian Diaspora to West Africa", incluido en la bibliografía.

7 En Cecilia Valdés se menciona que los barcos negreros vienen de la costa de Gallinas en África (245). En esta costa la factoría de Pedro Blanco también mantuvo contactos comerciales con el Porto de Galinhas, a 60 kilómetros al sur de Recife en Brasil. El nombre viene de la trata clandestina en el siglo XIX, cuando se decía que había gallinas nuevas en el puerto, el sinónimo para la llegada de un cargamento nuevo. También en Curaçao se hallan pruebas de la trata clandestina con esta costa. Joceline Clemencia menciona el baile-canción "Katibu ta galiña" ("el esclavo es una gallina"), un lamento que esconde una protesta camuflada de la condición esclava como pura mercancía (435).

Revista Iberoamericana, Vol. LXXVII, Núm. 235, Abril-Junio 2011, 501-515 
LA AFRICANÍA EN CARBONES SILVESTRES

Mientras que en "Mujer Negra", la referenciaa África constituye el recuerdo abstracto de una "costa perdida" y una "lengua ancestral", esta referencia se hace mucho más concreta en Carbones silvestres. Se despliega en los primeros dos poemas - "Manto" y "Funda de bambula"- como la visión de un sueño:

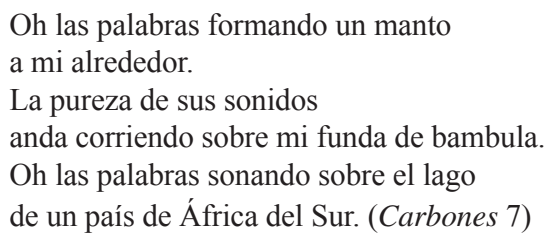

Inmediatamente después regresa el recuerdo de la trata con "la isla de Gorée en la palma de mi mano", y como antaño "vuelven los mercaderes .../ dando alaridos y golpeando/ empujando a mujeres y niños,/ y los mejores hombres del sur/ y de las costas/ hacia sus barcos sin regreso" (Carbones 8). Sin embargo, África sigue siendo una ausencia en el espacio público de Cuba, tema de otro poema, "Nombres" (Carbones 20-21). Comienza con la frase "Nombras a tu hijo Jesús/ y todos aplaudan arrobados" terminando con el verso: "Nadie se llama Oki todavía". De Jesús hasta Oki, mientras tanto, Morejón interpreta los significados de otros nombres en boga en épocas diferentes como Laura, César Augusto, Eduviges, William, Daisy, Nancy, Gladys, Katia, Misleidi, Yordanca, Yosvany, y Bladimir. Para cada una de las etapas-latina, inglesa y soviética-se describen las diferentes reacciones de "todos", las que, a partir de su primer entusiasmo "arrobado", van modificándose sucesivamente hasta cristalizar en "tanta historia lejana,/ ajena, temporalmente desechable, perfectamente hecha para el olvido". Solo ahora, después de la palabra "olvido" y el punto, sigue el verso final: "Nadie se llama Oki todavía", otra frase enfática orientada a la necesidad de cambio.

Debido a la división de Carbones silvestres en cinco secciones, cada una comprendiendo un número diferente de poemas, ${ }^{8}$ el poema "Elegía" adquiere una significación particular: se trata del poema más largo, cubriendo por sí solo toda una sección. En efecto, no es de sorprender que en este poema se hallen las claves para la explicación del título del volumen.

"Elegía" está dedicada a la memoria de Neyda Ulacia, apodada Chiquitica, una amiga íntima de la poeta y su familia. Para anunciar la importancia de su memoria, el poema abre con una metáfora asociada con uno de los milagros de Cristo: "Como una

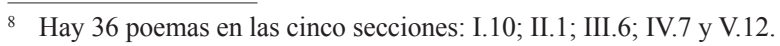

Revista Iberoamericana, Vol. LXXVII, Núm. 235, Abril-Junio 2011, $501-515$
ISSN 2154-4794 (Electrónico) 
fuente, Chiquitica/ multiplicaba los peces y los panes" (Carbones 27). Por consiguiente, se desarrolla un imaginario que concibe a Chiquitica como el símbolo de la metamorfosis:

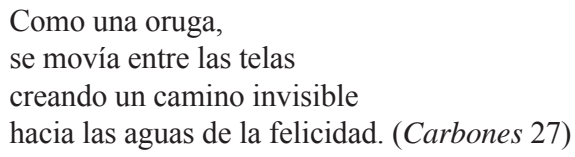

El imagen de la oruga se refiere a la predilección de Morejón por el género pictórico de la naturaleza muerta, nacido con la especialización en la historia natural de los siglos XVI y XVII. Proviene de la tradición de los Kunst- und Wunderkammer, en los que transformaron riquezas naturales y contactos con países extraeuropeos en alegorías. El género se especializaba en flores exóticas como tulipanes, narcisos o jacintos, así como animales (insectos, loros, monos) y objetos (conchas, piedras, vasos, plumas) procedentes de países lejanos. En combinación con la representación de flores, animales y objetos domésticos, aquellas imágenes pertenecientes a las colecciones de artificialia y naturalia eran testigos del lusus naturae -la naturaleza como pasatiempo (Phaf-Rheinberger, "El trópico" 98)-. La representación más altamente refinada de la oruga se encuentra en el libro patrón: Metamorfosis insectorum Surinamensium (1705) de la "great heroine", María Sybilla Merian, donde documenta los resultados de su investigación en una plantación en Suriname de una manera tan virtuosa que su reproducción adquiere, más allá de una mera ilustración científica, un valor altamente artístico (Freedberg 377-86). La oruga de Morejón continúa esta tradición de coleccionar delicadezas distinguidas y la clasifica en su epistemología poética del trópico urbano. En ésta, se destaca la exquisitez de Chiquitica: una "negra pulida como el diamante duro/ del río Níger", una "Negra de piel sin par", y donde también se sugiere la frontera con la muerte por medio de la presencia del lagarto y la iguana, esos reptiles enemigos de la oruga.

Chiquitica, "oruga de la calle Manrique", andaba con un "tabaco torcido" alisando "el cabello de las negras sentadas/ sobre ruecas dolientes/ quemando siempre el alma" (Carbones 29). ${ }^{9}$ Es un personaje altamente reconocido en el barrio Los Sitios, donde se ubica la calle Manrique en La Habana. Sus habitantes, los "fantasmas colorados", le rinden póstumo honor, desfilando bajo su balcón. Todos son personajes ya familiares de otros poemas de Morejón: Compay Segundo, Tejedor, la abuela Ángela, Chicho Ibáñez, María Teresa, Felipe el marinero, Joseíto el Mago, la Reina, Julia y Luisito Bequé, Nélida, Delia, Candito Ruiz, Vilma Valle, Lázaro Herrera y Guillermo Taylor. Es posible

9 El cabello es un motivo asociado con Nancy Morejón desde que Guillén publica su poema "Nancy" en 1972: "Su cabeza sin tostar, dicho sea para aludir a los tostadores y tostados negros burgueses que se queman la cabellera cada semana y viven esclavos del peluquero engañador" (Guillén 281). También Morejón dedica el poema "Pelo" (Carbones 22) a este motivo.

Revista Iberoamericana, Vol. LXXVII, Núm. 235, Abril-Junio 2011, 501-515 
interpretar este desfile como una paráfrasis de "este desfile silvestre", de Rimbaud. Es decir que la autora da prueba de que con estos personajes confiesa la identificación con su propio medio ambiente local.

Con este medio ambiente local como fondo se crea la atmósfera de una máxima intimidad, ya que Chiquitica está presente en la muerte de la madre, La China. Esto ocurre en los seis cuartetos en la parte central del poema, cuya regularidad contrasta con la métrica mucho más irregular de las otras estrofas. Sugiere una doble presencia de la muerte de un ser querido. Chiquitica sucumbió por ejercer el oficio de planchadora con una plancha a carbón:

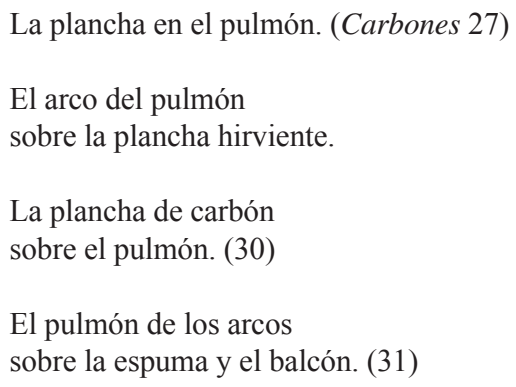

De esta manera, las elipsis acerca de la muerte de Chiquitica se inscriben en la tradición de la "Elegía de María Belén Chacón" (1934) de Emilio Ballagas. María Belén Chacón es una rumbera con "nalgas en vaivén", cuyo pulmón esta quemado por una plancha, en este caso sin carbón. Chiquitica, por tanto, es todo lo contrario a esta sensualidad atractiva de la mujer estereotípica del trópico. Es una habanera silenciosa con una individualidad impresionante: "nadie la vio llorar/ aunque lloraba./ Nadie la oyó gemir/ aunque gemía". Como todos los otros habitantes del barrio, es una descendiente orgullosa de los "sacos de carbón" del pasado. Sin embargo, la muerte causada por la plancha a carbón sugiere que este pasado ha dejado sus heridas. Para curarlas, la poeta escribe sus poemas "silvestres" como plantas medicinales, curadoras y benéficas.

Ya es casi lógico que las palabras de Chiquitica vienen "de algún barco remoto,/ bogando todavía frente a las costas fijas". De este modo, Morejón agrega un tono femenino a la "historia masculina" (DeLoughrey 73) de la "filosofía del mar", objeto de un campo emergente de investigación. Finley ya mencionó que, hoy día, el panfleto de Thomas Clarkson sirve como inspiración a muchos artistas plásticos. DeLoughrey opina que los autores del Caribe se han concentrado sobre todo en las aguas del Atlántico como el origen de la diáspora africana, tomando como ejemplos a Kamau Brathwaite de Barbados, Édouard Glissant de Martinica, John Hearne de Jamaica, Caryl Phillips de St. Kitts, y John D'Aguiar de Guyana. A su vez, en The French Atlantic Triangle (2008),

Revista Iberoamericana, Vol. LXXVII, Núm. 235, Abril-Junio 2011, $501-515$
ISSN 2154-4794 (Electrónico) 
Christopher L. Miller se refiere al campo emergente de la crítica literaria referente a África francófona (369-370) en este contexto, recordando que la primera novela de Sembène Ousmane Le Docker noir (1958) ya había planteado este tema. Otro ejemplo se encuentra en el libro de Joseph-Désiré Otabela y Sosthène Onomo Abena (2008) sobre Donato Ndongo-Bidyogo, un reconocido autor de Guinea Ecuatorial. Los editores reproducen uno de sus primeros cuentos "La travesía", publicado bajo pseudónimo en 1977, en el que Ndongo se identifica con los africanos esclavizados en un barco negrero. Otros escritores contemporáneos siguen escribiendo sobre esta temática. El autor angolano José Eduardo Agualusa narra el viaje del último buque con carga clandestina de Angola a Brasil en 1876 en Nação crioula (2001), el nombre del barco en cuestión. O en Chile retrata Ricardo Gattini, en su novela histórica El barco de ébano (2008), la historia de su destino en Valparaíso en 1809. Y en The Air of Liberty (Phaf-Rheinberger) se recorre todo el arsenal de las conexiones con las anteriores colonias holandesas en Brasil, Suriname, y Curaçao existentes en el Atlántico del Sur al manifestar que el barco negrero como motivo narrativo es sumamente actual.

La representación múltiple del imaginario oceánico y su ícono movedizo como signo de la reconstrucción del Nexus entre el pasado y el presente hace palpable que, en la actualidad, se sienta la obligación de recuperar y cuestionar esta memoria en la conciencia crítica. Para Morejón, esta tarea está en la raíz de toda su obra. La coincidencia entre sus lecturas de Rimbaud y los "años románticos" de la Revolución Cubana a principios de la década de 1960 le dieron amparo para escoger este camino. $\mathrm{Su}$ particularidad reside en que, a partir de entonces, desarrolla un hilo que dirige la mirada hacia la preocupación literaria en una antigua colonia, en una república todavía replegada en las fauces de la Guerra Fría. No podría encontrarse una mejor o más fiel traductora de las etapas diferentes de esta situación y, por ello mismo, Morejón se ha establecido como una poeta que, con su obra, se siente particularmente unida con esta realidad histórica. Se ha demostrado en este ensayo además que su arraigo a La Habana está sólidamente unido con la filosofía del mar del siglo xIx. El análisis de su obra también llama la atención sobre el hecho de que sus referencias a la literatura cubana contribuyen de manera excepcional a estos estudios en pleno desarrollo sobre el alma peregrina de los barcos en el mar y su cargamento humano.

\footnotetext{
Revista Iberoamericana, Vol. LXXVII, Núm.235, Abril-Junio 2011, 501-515 
BiBLIOGRAFÍA

Agualusa, José Eduardo. Nação crioula. Rio de Janeiro: Gryphus, 2001.

Arnold, A. James. Modernism \& Negritude. The Poetry and Poetics of Aimé Césaire. Cambridge, MA: Harvard UP, 1981.

Ballagas, Emilio. “Elegía de María Belén Chacón”. Órbita de la poesía afrocubana 192837 (antología) 1938. Ramón Guirao, ed. Nendeln: Kraus Reprint, 1970. 107-108.

Berjola, Giovanni. Arthur Rimbaud et le complexe du damné. Caen: Lettres Modernes Minard, 2007.

Clemencia, Joceline. "Katibu ta galiña: From Hidden to Open Protest in Curaçao." A History of Literature in the Caribbean. Vol. 2. A. James Arnold, ed. Amsterdam: John Benjamins, 2001. 433-42.

Cordones-Cook, Juanamaría, ed. Introducción / Introduction. Looking Within / Mirar adentro. Selected Poems of Nancy Morejón, 1954-2000. Detroit: Wayne State UP, 2003. 18-63.

DeLoughrey, Elizabeth M. Routes and Roots. Navigating Caribbean and Pacific Island Literatures. Honolulu: U of Hawai P, 2007.

Finley, Cheryl. "Erinnerung verpflichtet. Die Ikone des Sklavenschiffs in der Vorstellungswelt des Black Atlantic." Der BlackAtlantic. Tina Campt y Paul Gilroy, eds. Berlin: Haus der Kulturen der Welt, 2004. 248-63.

Freedberg, David. "Science, Commerce, and Art: Neglected Topics at the Junction of History and Art History." Art in History-History in Art: Studies in Seventeenth Century Dutch Culture. David Freedberg and Jan de Vries, eds. Cambridge: Oxford UP, 1996. 377-428.

Gattini, Ricardo. El barco de ébano. Chile: Grijalbo, 2008.

Gilroy, Paul. The Black Atlantic. Modernity and Double Consciousness. Cambridge, MA: Harvard UP, 1993.

Guillén, Nicolás. "Nancy". Obra poética 1958-1972. Angel Augier, ed. La Habana: UNEAC, 1974. 280-81.

Kutzinski, Vera M. Sugar's Secrets. Race and the Erotics of Cuban Nationalism. Charlottesville: UP of Virginia, 1993.

Lezama Lima, José. "La calle de Rimbaud". Tratados en La Habana. Las Villas: Universidad Central de Las Villas, 1958. 102-6.

"Una fragata con las velas desplegadas". Fragmentos a su imán. Cintio Vitier y José Agustín Goytisolo, pról. Barcelona: Lumen, 1977. 64-65.

Martínez Fortún y Foyo, José A. El Diario de La Habana. Índices y sumarios. La Habana: Ed. mimeografiada, 1955.

Miller, Christopher L. The French Atlantic Triangle. Literature and Culture of the Slave Trade. Durham: Duke UP, 2008.

Revista Iberoamericana, Vol. LXXVII, Núm. 235, Abril-Junio 2011, $501-515$
ISSN 2154-4794 (Electrónico) 
Morejón, Nancy. Carbones silvestres. La Habana: Letras Cubanas, 2005.

Cuerda veloz: antología poética, 1962-1992. La Habana: Letras Cubanas, 2005.

Ensayos. Trinidad Pérez Valdés, sel. y pról. La Habana: Letras Cubanas, 2005.

España en Nicolás Guillén. La Habana: Unión, 2005.

Ndongo-Bidyogo, Donato. "La travesía". Entre estética y compromiso. La obra de Donato Ndongo-Didyogo. Joseph-Désiré Otabela y Sosthène Onomo Abena, eds. Madrid: Universidad Nacional de Educación a Distancia, 2008. 91-99.

Novás Calvo, Lino. Pedro Blanco, el negrero. Biografía novelada. La Habana: Letras Cubanas, 1997.

Pastor, Beatriz. Discurso narrativo de la conquista de América. La Habana: Casa de las Américas, 1983.

Phaf-Rheinberger, Ineke. The 'Air of Liberty'. Narratives of the South Atlantic Past. Amsterdam: Rodopi, 2008.

"El trópico y su nexo con la naturaleza muerta. Una epistemología poética de Nancy Morejón". Tierra de libertad y paisajes del Caribe. Ineke Phaf-Rheinberger, ed. Berlin: Wissenschaftlicher Verlag, 2005. 97-109.

y Rina Walthaus. "Ícaro, Narciso, el poeta. Una interpretación de dos mitos en la obra de Góngora y en la de Lezama Lima". Década. J. Lechner y F. Van Putte, eds. Leiden: Universidad de Leiden, 1980. 137-90.

Rimbaud, Arthur. Dos poemas de Rimbaud. Nancy Morejón, trad. Matanzas: Vigía, 1991. Sämtliche Dichtungen. Französischund Deutsch. Walther Küchler, ed. Heidelberg: Verlag Lambert Schneider, 1982.

Strickrodt, Silke. "The Brazilian Diaspora to West Africa in the Nineteenth Century." AfricAmericas. Itineraries, Dialogues, and Sounds. Ineke Phaf-Rheinberger y Tiago de Olivieira Pinto, eds. Madrid: Iberoamericana, 2008. 36-68.

Veit-Wild, Flora. Writing Madness. Borderlines of the Body in African Literature. Oxford: James Curry, 2006.

Villaverde, Cirilo. Cecilia Valdés o la Loma del Ángel 1886. La Habana: Consejo Nacional de Cultura, 1964.

Revista Iberoamericana, Vol. LXXVII, Núm. 235, Abril-Junio 2011, 501-515 
